\title{
A Metapsicologia do Infamiliar e seu Lugar na Constituição Psíquica
}

\author{
Fabiano Chagas Rabêlo* \\ Universidade Federal do Delta do Parnaíba - UFDPar, Parnaíba, PI, Brasil \\ ORCID: http://orcid.org/0000-0001-5026-8396 \\ Karla Patrícia Holanda Martins** \\ Universidade Federal do Ceará - UFC, Fortaleza, CE, Brasil \\ ORCID: http://orcid.org/0000-0003-3242-6287
}

\begin{abstract}
RESUMO
$\mathrm{O}$ artigo propõe discutir a inserção do Unheimliche no desenvolvimento do modelo de aparelho psíquico psicanalítico, relacionando-o com alguns conceitos metapsicológicos que o precederam e outros, posteriores, que se beneficiaram de sua influência. Para tanto, priorizase o tema da constituição psíquica na sua relação com as paramnésias. O conceito de narcisismo é trazido à baila para questionar as diferenças e semelhanças entre as definições de Infamiliar (Unheimliche) e estranhamento (Entfremdung). Comenta-se o conto de Borges $O$ outro, o artigo freudiano Um distúrbio de memória na Acrópole e o texto de Tausk Ibsen, Der Apoteker para estabelecer um paralelo entre a ficção literária e as valências dos sentimentos de desrealização e dessubjetivação na clínica das neuroses. O conceito de fenômeno transicional de Winnicott e a problemática da alteridade que Lacan apresenta, em dois momentos de seu ensino, são debatidos a partir dos desdobramentos em torno do Infamiliar e da cisão do eu. Ao final, indaga-se o estatuto metapsicológico do Infamiliar como uma modalidade particular do retorno do recalcado, que mobiliza os limites do recalque primário, promovendo uma subversão temporária das fronteiras do $\mathrm{Eu}$ e da realidade, com consequências para pensarmos os modos diferenciais da constituição psíquica.
\end{abstract}

Palavras-chave: infamiliar, estranhamento, paramnésia, narcisismo, constituição psíquica.

\section{The Uncanny's Metapsychology and its Place on Psychic Constituition}

\begin{abstract}
The article discusses the insertion of the Unheimliche in the development of the model of psychoanalytic psychic apparatus, relating it to some metapsychological concepts that preceded it and others, later, that benefited from its influence. To this end, the theme of psychic constitution is prioritized in its relationship with paramnesia. The concept of narcissism is brought up to question the differences and similarities between the definitions of Uncanny (Unheimliche) and estrangement (Entfremdung). One analyses a Borges short story The other, the freudian article A Memory Disorder in the Acropolis and the text by Tausk Ibsen, Der Apoteker to establish a parallel between literary fiction and the valences of feelings of derealization and desubjectivation in the clinic of neuroses. Winnicott's concept of
\end{abstract}

ISSN $1808-4281$ 
transitional phenomenon and the problem of otherness that Lacan presents in two moments of his teaching are debated from the link between the concepts of Uncanny and split of the self. In the end, the metapsychological status of the Uncanny is investigated as a particular modality of return of the repressed, which mobilizes the limits of primary repression, promoting a temporary subversion of the boundaries of ego and reality, with consequences for thinking about the differential modes of psychic constitution.

Keywords: uncanny, estrangement, paramnesia, narcissism, psychic constitution.

\section{La Metapsicología de lo Ominoso y su Lugar en la Constitución Psíquica}

\section{RESUMEN}

El artículo discute la inserción del Unheimliche en el desarrollo del modelo de aparato psíquico psicoanalítico, relacionándolo con algunos conceptos metapsicológicos que lo precedieron y otros que se beneficiaron de su influencia. Para ello, se prioriza el tema de la constitución psíquica en su relación con la paramnesia. Se plantea el concepto de narcisismo para cuestionar las diferencias y similitudes entre las definiciones de Ominoso (Unheimliche) y alejamiento (Entfremdung). Se analiza un cuento de Borges El otro, el artículo freudiano Un trastorno de la memoria en la acrópolis y el texto de Tausk Ibsen, Der Apoteker para establecer un paralelismo entre la ficción literaria y las valencias de los sentimientos de desrealización y desubjetivación en las neurosis. El concepto de Winnicott de fenómeno transicional y el problema de la alteridad que Lacan presenta en dos momentos de su enseñanza son debatidos desde el vínculo entre los conceptos de Ominoso y escisión del yo. Al final, se problematiza lo Ominoso como una modalidad de retorno de lo reprimido, que moviliza los límites de la represión primaria, promoviendo una subversión temporal de los límites del Yo, con consecuencias para pensar en los modos diferenciales de constitución psíquica.

Palabras clave: ominoso, alejamiento, paramnesia, narcisismo, constitución psíquica.

O Unheimliche (Freud, 1919/1997g), termo traduzido para o português como Infamiliar (Iannini \& Tavares, 2019), Estranho, Inquietante, Sinistro, Macabro e Lúgubre (Hans, 1998), constitui o tema deste trabalho. Optou-se pela primeira por entender que ela contribui para contornar algumas ambiguidades que podem surgir da contraposição desse conceito com outros termos abordados, a saber: o estranhamento (Entfremdung) e Estranho (Fremd).

Do exposto, propõe-se investigar o estatuto metapsicológico do Infamiliar, assim como os problemas teóricos e clínicos que o precederam e influenciaram a sua formulação. Coloca-se em evidência os procedimentos heurísticos e metodológicos envolvidos nesse 
processo, assim como a intensa interlocução com a literatura, que constitui uma forte marca do ensaio de Freud dedicado a esse assunto.

Sustenta-se que a proposta do Unheimliche resulta de um longo, complexo e refinado trabalho, que se desdobrou na interface entre clínica, literatura, etimologia e estudos culturais. Sua confecção exigiu a coordenação de diferentes procedimentos aplicados no decorrer das duas primeiras décadas de pesquisa psicanalítica. Parte-se da constatação de que a apreensão conceitual do sentimento do Infamiliar constituiu uma difícil e delicada tarefa, haja vista que tal fenômeno se furta a um modo de investigação mais rígido e diretivo, exigindo uma abordagem oblíqua, flexível, quando não fragmentada (Massechelein, 2011).

Sublinha-se que a definição do Unheimliche está intensamente conectada à metapsicologia psicanalítica. Sua assimilação ao modelo do funcionamento de aparelho psíquico acabou por reenviar Freud a zonas ainda obscuras e não suficientemente exploradas de seu projeto de investigação. Portugal (2006) assinala que o artigo sobre o Infamiliar situase em um ponto de virada na obra de Freud. Nas palavras de Cesarotto (1996), trata-se de "um momento de transição irreversível" (p. 109), no qual algumas dificuldades e fios soltos amealhados sob a égide da primeira tópica são reavaliados, preparando terreno para as reformulações das décadas de 1920 e 30 . Nesse sentido, é importante ter em vista a sintonia do Unheimliche com os desafios clínicos com os quais a psicanálise foi confrontada após a Primeira Guerra Mundial, tais como as neuroses de guerra e a revisão da teoria do trauma (Gay, 1989).

Apesar dessa intensa conexão com a metapsicologia, percebe-se a carência de articulações explícitas na obra de Freud que relacionam o Unheimliche a outros conceitos psicanalíticos. Ao contrário de seu modo de elaboração usual, que, via de regra, opera pela conservação das categorias teóricas, que são gradualmente enriquecidas e tensionadas a partir das discussões clínicas e da contraposição com outros conceitos psicanalíticos (Mezan, 2013), Freud raramente retorna ao comentário do Infamiliar após a sua publicação. Tal lacuna é percebida de forma mais marcante no texto Um distúrbio de memória na Acrópole (Freud, 1936/1997k). Sua leitura transmite àqueles já familiarizados com o ensaio de 1919 a sensação de que o autor está durante toda a sua extensão a se referir ao Unheimliche, muito embora em nenhum momento tal termo seja mencionado.

Entende-se que a escassez de referências ao Infamiliar após 1919 pode causar a falsa impressão de que ele é uma referência de menor importância ou mesmo uma digressão pontual no percurso freudiano, opinião que persistiu por muito tempo no seio da comunidade psicanalítica. Sobre esse ponto, é importante lembrar que a categoria do Unheimliche só 
ganhou evidência a partir da Segunda Guerra Mundial, sobretudo em função do trabalho de autores de outros campos como a arte, a filosofia, os estudos culturais e literários (Massechelein, 2011). Nesse mesmo período, o Unheimliche volta ao foco do interesse dos psicanalistas, como é possível se constatar por meio dos trabalhos de Lacan (1959-1960/1997, 1964/1998) e Winnicott (1945/2000, 1953/1975). Os textos desses autores agora referidos são comentados ao longo deste artigo.

Com efeito, defende-se que o Infamiliar é uma importante referência do edifício teórico psicanalítico que possui um amplo potencial a ser explorado. Ressalta-se ainda a sua atualidade e a sua vocação transdisciplinar, o que o torna um valioso instrumento de investigação do processo de constituição psíquica, tema que exige do psicanalista uma atenção particular à complexa simbiose existente entre os pares sujeito e alteridade, psiquismo e cultura, Eu e realidade. O Infamiliar (Freud, 1919/1997g) é tomado aqui como um resto do processo de constituição psíquica. Sua irrupção lança luz sobre a dinâmica de uma ação psíquica estruturante, o narcisismo, que se mantém de certa forma aberta e inconcluso no decorrer de toda a vida e que, por isso, está sujeito a flutuações.

Em função da abrangência do tema, decidiu-se delimitar o escopo deste trabalho à conexão do Infamiliar com os atos falhos, sobretudo as paramnésias - como se costuma designar os transtornos de memória -, explorando a conexão desses fenômenos com a clínica e a literatura. Este texto possui a seguinte estrutura: no primeiro tópico, introduz-se a definição do Infamiliar, relacionando-o com o problema da constituição psíquica. Comenta-se então um fragmento do conto de Borges (1975/2009), O outro, para acentuar o vínculo entre literatura, o Unheimliche e as paramnésias. No tópico seguinte, partindo da leitura do artigo no qual Freud (1936/1997k) versa sobre um distúrbio de memória na Acrópole, questiona-se o nexo entre o Unheimliche e os sentimentos de estranhamento (Entfremdung), desrealização e dessubjetivação. Discute-se daí a participação do mecanismo de cisão do Eu na gênese do sentimento do Infamiliar. No último tópico, comenta-se um texto no qual Tausk (1919/1983) apresenta um lapso de memória, relacionando-o ao sentimento do estranho (Fremd). Em seguida, faz-se referência à ideia de fenômeno transicional, tal como proposto por Winnicott (1953/1975), para sublinhar a mobilização da estrutura da fantasia e o endereçamento a uma alteridade, que comparecem nos fenômenos de desrealização e dessubjetivação. Estabelece-se ainda uma ligação entre o Unheimliche e a discussão que Lacan faz das valências da alteridade no processo de constituição psíquica nos seminários 7 (Lacan, 1959-60/1997) e 11 (Lacan, 1964/1998), com foco nesse último. 


\section{Método}

Este artigo constitui uma revisão bibliográfica, de caráter narrativo, ensaístico (Severino, 2013), que problematiza as explicações freudianas sobre os processos de constituição psíquica, organização narcísica e construção da realidade. O foco recai na relação entre o Infamiliar, as paramnésias e os sentimentos de desrealização e dessubjetivação. Optouse por limitar o recorte deste trabalho à apreciação dessa temática no campo das neuroses. Isso quer dizer que a discussão sobre as manifestações do Unheimliche na clínica das psicoses, em razão de sua especificidade e complexidade, não é contemplada neste trabalho.

Além de textos psicanalíticos, de Freud, de seus colaboradores - em especial, Victor Tausk - e de referências históricas e biográficas, toma-se como apoio as contribuições de comentadores, da psicanálise e de outros campos, que se debruçaram na investigação do Unheimliche. Explora-se um trecho de um conto de Borges (1975/2009) que dialoga de perto com a temática do Infamiliar. A intenção dessa inserção é explorar a potência da conexão entre a clínica psicanalítica e a literatura. Em relação à interpretação dos dados, explicita-se a influência recebida de alguns autores pós-freudianos que são citados no decorrer deste artigo, no caso: J. Lacan (1959-1960/1997, 1964/1998) e D. Winnicott (1947/2000, 1953/1975).

Adota-se neste artigo a expressão Infamiliar como tradução para o Unheimliche. Trata-se de um neologismo ainda não dicionarizado que surgiu numa versão recentemente publicada do ensaio freudiano (Iannini \& Tavares, 2019). Em comparação com outras traduções, considera-se tal solução pertinente, haja vista que, ao excluir a menção ao radical Estranho (Fremd), evita a sobreposição dos termos Unheimliche e Entfremdung. Deve-se atentar, por outro lado, que esse problema estaria igualmente afastado com as palavras Sinistro, Macabro ou Lúgubre (Hans, 1996), que já são dicionarizadas e amplamente utilizadas na linguagem corrente. No entanto, nesse caso, perde-se a sobredeterminação do qual Freud tanto chama atenção: a coalescência dos sentidos contrários - o familiar e o infamiliar - que é proporcionada pelo prefixo negativo un, no alemão, e do in, no português. Daí a decisão pelo Infamiliar.

Esclarece-se ainda que se utilizou a palavra estranhamento para indicar a ideia de Entfremdung e estranho para designar o adjetivo/substantivo fremd/Fremd. Durante o texto, os termos originais em alemão comparecem de forma intercalada às suas respectivas traduções, de forma a salientar a especificidade de cada um desses fenômenos. 


\section{O Infamiliar e o Processo de Constituição Psíquica}

Este artigo parte da constatação de que o interesse de Freud pelo Infamiliar o levou a reavaliar as bases de sua explicação do processo de constituição psíquica, agregando mais subsídios, assumindo outros pontos de vista e se permitindo estabelecer inferências mais ousadas. Percebe-se, nesse contexto, a retomada de especulações e hipóteses amealhadas durante as duas primeiras décadas do séc. XX, a exemplo do conceito de pulsão de morte (Numberg \& Federn, 2015). Tal projeto, no entanto, não perde de vista o elo com a clínica, seja em função da atenção dada a questões que despontaram da práxis psicanalítica, como no caso das neuroses de guerra e da reação terapêutica negativa, seja pela retomada de alguns temas ainda não suficientemente equacionados pela metapsicologia, como as teorias do trauma, da angústia e do dualismo pulsional (Gay, 1989).

Assume-se a premissa de que, para a psicanálise, o processo de constituição psíquica deve ser entendido como resultado de uma relação sempre singular e, de certa forma, plástica de cada indivíduo com uma alteridade que lhe é anterior, encarnada pela linguagem, pela cultura e, de modo mais específico, pelas pessoas que servem de suporte às funções materna e paterna (Lacan, 1956-57/1995). O Infamiliar, nesse sentido, pode ser avaliado como o remanescente de um momento de estruturação mais fundamental que se mantém inconcluso e inacabado, mesmo em situações não patológicas. As suas manifestações, por conseguinte, lançam luz sobre esse momento de difícil apreensão do desenvolvimento psíquico - ao mesmo tempo atávico e atual - no qual o sujeito em desenvolvimento se separa do Outro e passa a se orientar pelo seu próprio desejo a partir de sua fantasia fundamental (Lacan, 1964/1998).

O sentimento do Infamiliar vem mostrar que cada ser humano possui uma valência própria dessa alteridade fundadora, que é suscetível a flutuações no decorrer de toda a vida. Tais inflexões são perceptíveis por meio de alguns fenômenos - tais como as paramnésias que reverberam as instabilidades do estatuto da realidade no psiquismo.

Argumenta-se que o Unheimliche é efeito de um abalo da estrutura narcísica após essa ter alcançado um determinado estágio de organização. Sabe-se que, para Freud (1914/1997e), faz-se necessário a intervenção de uma ação psíquica para que o Eu venha a se constituir, uma vez que tal instância não é inata, tampouco pode ser apresentada como o correlato imediato das funções biológicas, conforme a hipótese anterior, posteriormente abandonada, que vincula o Eu a uma suposta tendência de autopreservação (Freud, 1905/1997a, 1911/1997b). O ensaio sobre o Infamiliar (Freud, 1919/1997g) permite afirmar que essa ação que dá origem ao Eu nunca está totalmente assegurada e que nenhuma força da natureza lhe serve de garantia. 
Consequentemente, as fronteiras do $\mathrm{Eu}$ encontram-se perpetuamente ameaçadas pelas manifestações do desejo e da pulsão e pelas variações bruscas do ambiente. Tal fato se deixa perceber por meio das alterações psíquicas encontradas durante o sono (Freud, 1914/1997e), em algumas situações traumáticas (Freud, 1920/1997h), no trabalho de luto (Freud, 1914/1997e) e em certos fenômenos do dia a dia, tais como os sentimentos de desrealização e dessubjetivação (Freud, 1914/1997d).

Entende-se daí que a concepção do Unheimliche não seria possível de ser formulada sem o lastro da discussão sobre o narcisismo, cuja influência repercute amplamente nos textos freudianos da segunda década do século XX. A veracidade dessa assertiva pode ser verificada quando se lê que a irrupção do sentimento do Infamiliar envolve um movimento de regressão a um momento do desenvolvimento - o narcisismo primário - em que os limites entre o Eu e o mundo ainda não estavam suficientemente demarcados (Freud, 1919/1997g).

Deve-se ponderar, todavia, que esse movimento regressivo não é suficiente para explicar o Unheimliche. É necessário acrescentar outra ação psíquica em sentido contrário de restituição narcísica da realidade - que possibilita a apreensão, mesmo que de modo parcial e efêmero, desse sentimento, assim como o seu compartilhamento no limiar entre a ficção e o testemunho de uma experiência subjetiva.

A esse respeito, é importante lembrar que, para Winnicott (1945/2000), uma vez alcançado um determinado nível de organização narcísica, certos vetores, mesmo que sofram oscilações, prevalecem no sentido de restituição das fronteiras psíquicas. Tal argumento, no nosso entendimento, impõe uma abordagem diferenciada da incidência dos sentimentos de desrealização e dessubjetivação nas neuroses e nas psicoses. Daí a restrição do escopo deste artigo à análise da dinâmica desses fenômenos nas neuroses.

Por outro lado, a afirmação de Winnicott (1945/2000) permite sustentar que esse retorno ao equilíbrio após uma vivência desestabilizadora demanda um trabalho de ajuste na relação com o outro e a realidade, o que não acontece sem uma cota de desorientação, vertigem e angústia.

J. L. Borges (1899-1986), no conto O outro (1975/2009), ilustra muito bem esse movimento de báscula entre duas situações aparentemente antagônicas, de dessubjetivação e retificação narcísica, que compõe a arquitetura do Infamiliar. Esse texto aborda um acontecimento que o autor considera intensamente real e, ao mesmo tempo, evanescente: o encontro em sonho com ele mesmo várias décadas mais jovem. Em suas palavras: "Não o escrevi de imediato porque o meu primeiro propósito foi de esquecê-lo, para não perder a 
razão" [...] "Sei que foi quase atroz enquanto durou" [...] "penso que, se o escrever, os outros lerão como um conto e, com os anos, talvez o seja pra mim" (p. 07).

Sublinha-se que, tanto em Freud como em Borges, a ficção ou a fantasia não se opõe à realidade. Ao invés disso, ela destaca um ponto de opacidade presente na realidade, que passa então a ser bordejado por um arranjo simbólico e imagético (Rabêlo, Pereira, \& Furtado, 2011). A fantasia, portanto, recobre o real, tal como uma pérola recobre o grão de areia. Ela é a janela por meio da qual se franqueia o acesso à realidade (Lacan, 1964/1998). Deve-se, portanto, situar esses três termos - real, realidade e fantasia - como distintos, mas correlatos (Lacan, 1959-1960/1997).

É possível afirmar daí que o Unheimliche resulta de uma experiência de desrealização, que desencadeia um curto-circuito nas coordenadas entre o dentro e o fora, entre o já assimilado e o não reconhecido, e que abre a possibilidade para um novo delineamento dos limites narcísicos da realidade. Entende-se por limite narcísico da realidade o estabelecimento de fronteiras entre o interior e o exterior psíquico. O problema que a investigação psicanalítica aponta - em consonância com a literatura - é que a oposição entre o intra e o extrapsíquico não recobre os pares conhecido/desconhecido, estranho/familiar, fantasia/realidade ou corpo/mundo externo.

Para avaliar essa questão, é importante levar em consideração que, para a psicanálise, o acesso à realidade não é uma função primária naturalmente garantida pelas sensações e percepções. O sentimento de realidade só se constitui por meio do compartilhamento de referências simbólicas dentro de uma comunidade de indivíduos (Winnicott, 1945/2000). Por conseguinte, os objetos externos só ganham valência psíquica quando representados na interação com uma alteridade, a partir das experiências de prazer e desprazer (Martins, 2014). Apenas a partir dessas representações, o sujeito pode verificar os efeitos de uma ação coordenada - no vocabulário freudiano, ação específica (Freud, 1911/1997b) -, que lhe serve de referência para que ele se decida pelo investimento da libido em um dado objeto ou pela sua retração e redirecionamento para outros fins.

Pode-se dizer daí que, como efeito inexorável do processo de constituição psíquica, há um interior estranho que não é reconhecido como parte integrante do $\mathrm{Eu}$, assim como um exterior não representado que não está integrado à realidade. Defende-se que esse estranho interior e esse exterior não reconhecível podem ser incluídos no registro que Lacan (19591960/1997) denomina real.

Conclui-se então pela importância da acolhida e problematização dos relatos acerca das vivências do sentimento do Infamiliar. Como se pode perceber no conto, a irrupção desse 
sentimento mobiliza o âmago da fantasia e da estrutura psíquica de cada sujeito, fazendo apelo a uma elaboração simbólica que não se limita às referências socialmente sancionadas. Trata-se, antes, de uma convocação a um testemunho acerca de um conteúdo que não pode ser compartilhado, mas que possui uma urgência subjetiva e um peso de verdade.

Vale pontuar que a discussão sobre o Infamiliar em Freud remete à afirmação feita dois anos antes, de que o Eu não é senhor em sua própria casa (Freud, 1917/2001). Nesse momento, Freud vincula a impossibilidade do $\mathrm{Eu}$ em se assenhorar de seus processos psíquicos internos às feridas narcísicas da humanidade. Tais feridas estão presentes como obstáculos na produção e assimilação do conhecimento.

Essa discussão é retomada no contexto da segunda tópica, na defesa da primazia do Isso (Es) sobre o Eu (Ich). Resgata-se aqui a metáfora proposta por Freud (1923/1997i, 1933/1997j) de que o Eu pode ser entendido como um pequeno jockey que monta um enorme e potente cavalo, o Isso. Essa imagem permite descrever o sentimento do Infamiliar como um instante de vacilação da ilusão de controle que o primeiro supõe exercer sobre o segundo. Daí o imbricamento do Unheimliche no desamparo (Hilflosigkeit), que é uma condição estrutural e estruturante do psiquismo (Martins, 2014; Portugal, 2006).

Ainda no interior da obra freudiana, pode-se delinear uma conexão entre o Unheimliche e a fruição estética do efêmero (die Vergänglichkeit) (Freud, 1916/1997f). A experiência de dissolução de fronteiras do Eu perpetrada pelo Infamiliar permite um vislumbre do caráter frágil e artificial das defesas narcísicas, sem, contudo, desqualificar a sua importância. Constatar que o controle do Eu sobre os processos psíquicos internos e o ambiente que o circunda é limitado e fluído pode ensejar uma atitude estética e subjetiva diferenciada. A partir de uma mudança de posição subjetiva incitada pela irrupção do Infamiliar, é possível que aquilo que se apresenta inicialmente como instável e ameaçador seja avaliado de outra perspectiva, como a manifestação pontual de uma verdade psíquica latente.

Desse modo, tanto da perspectiva da ética psicanalítica como da literatura borgiana, não é apenas o que é permanente e previsível que deve ser acolhido, mas, sobretudo, as manifestações do Isso que não encontram representação nas expectativas narcísicas: o intermitente, dissonante e angustiante. Acolher uma fala que promova a elaboração desse material é, ao mesmo tempo, um desafio clínico, ético e estético.

Se a fantasia se caracteriza como uma proteção frente ao real e um enquadre que organiza e dá consistência à realidade (Lacan, 1964/1998), ela também constitui uma via de acesso e mobilização do real, que, no nosso entendimento, pode ser explorada por meio das vivências de desrealização e dessubjetivação. 


\section{Infamiliar, Estranhamento e Ato Falho}

A referência ao conto no tópico anterior nos desafia a esboçar uma aproximação entre a experiência abordada por Borges e a vivência narrada por Freud (1936/1997k) no escrito Um distúrbio de memória na Acrópole. Embora não conste nele uma menção direta ao conceito de Unheimliche, entende-se que esse texto oferece uma análise detalhada do processo de gênese e eclosão do sentimento do Infamiliar (Portugal, 2006, D’Agord, Triska, Sudbrack, \& Sippert, 2012).

Nesse artigo, Freud (1936/1997k) narra uma experiência pessoal: um intenso sentimento de desrealização que lhe irrompe durante a sua primeira visita à Grécia. Assim como no conto de Borges, há nesse relato um hiato de mais de três décadas entre o acontecimento e a sua escrita (Portugal, 2006).

O texto - originalmente, uma carta destinada ao escritor francês Romain Roland (1866-1944) - descreve uma sensação de descompasso entre a percepção da realidade e a sua validação psíquica. No entanto, não se trata aqui de uma perturbação ou bloqueio do fluxo da percepção. Há, mais precisamente dizendo, uma recusa pré-intelectual, inconsciente e transitória de que Freud estava lá, naquele momento, de frente a Acrópole. A percepção funciona a contento, mas as informações que ela apresenta não são validadas. É como se tudo que Freud viveu ali remetesse a vida de outra pessoa (Freud, 1936/1997k).

Por conseguinte, o fenômeno do duplo (Doppelgänger) - conforme sustentado por O. Rank (1914) a partir das histórias de O. Wilde, R. L. Stevenson, E. T. A. Hoffmann e E. A. Poe - adequa-se muito bem às descrições de Borges e Freud. Na experiência do duplo, tem-se que um processo psíquico, um estranho interior sobre o qual o Eu não possui nenhuma ingerência, que não é reconhecido como parte integrante do $\mathrm{Eu}$, mas que, ao mesmo tempo, mantém uma vinculação muito forte e indissolúvel com ele, é então projetado para fora e tratado como uma manifestação distorcida de si mesmo.

Percebe-se nesse fenômeno os efeitos de uma cisão psíquica (Spaltung), que restringe a influência de uma parcela consciente do $\mathrm{Eu}$, que se torna um espectador com reduzido poder de ingerência sobre seus conteúdos interiores (Freud, 1940/19971). Tal cisão, segundo Freud, faz com que algumas tendências psíquicas possam se beneficiar de um processo de elaboração e representação, enquanto outras tenham seu desenvolvimento interrompido ou retardado. Decorre daí a coexistência na fantasia de materiais pertencentes a momentos diferentes do desenvolvimento psíquico e que possuem distintos graus de elaboração. 
Alguns desses conteúdos e tendências pulsionais não são reconhecidos ou significados como parte integrante do Eu. Tornam-se, por assim dizer, produções psíquicas escotomizadas. Seu desenvolvimento ocorre à revelia da influência do processo secundário e da prova realidade. Sua força latente se deixa perceber nos atos falhos, de modo mais amplo, mas encontra seu paroxismo no sentimento do Infamiliar.

Segundo Portugal (2006), o sentimento do Unheimliche é produto de um alargamento da fenda no $\mathrm{Eu}$, que constitui uma cicatriz residual permanentemente vulnerável do recalque primário. Nas palavras da autora, o Infamiliar implica no retorno "do Outro primordial, dotado de um valor que um dia foi absoluto" (Portugal, 2006, p. 99).

No texto que trata da visita a Acrópole, Freud (1936/1997k) associa a vivência que ele narra às impressões deixadas pelas ilustrações que vira nos livros da escola quando criança e a certos aspectos de sua relação com o seu pai, que morrera sem conhecer a Grécia. Assim como no conto de Borges, foi necessário um longo tempo de elaboração para que essa experiência e os seus determinantes fossem conectados e subjetivados.

Enfatiza-se a indicação de um período de mau humor - aparentemente desmotivado que se abateu sobre Freud antes de sua chegada a Atenas. Nas suas palavras, essa mudança de estado afetivo constituiu um preâmbulo do sentimento de desrealização que ele logo experimentaria. Tal detalhe é importante, pois leva a conclusão de que a eclosão do Unheimliche possui uma arquitetura, uma estrutura própria, que envolve um arranjo peculiar entre afeto e representação, assim como um curso diacrônico de evolução.

Ainda nesse texto de 1936, Freud propõe uma interessante comparação entre a sua vivência na Acrópole e os sentimentos de déjà vu, déjà raconté e dejá experimenté, a respeito dos quais ele havia escrito duas décadas antes. Segundo Freud (1914/1997d), tais expressões designam tipos específicos de paramnésias. Respectivamente, a impressão de já se ter visto, contado ou experimentado uma situação que não aconteceu. Conforme o autor (Freud, 1936/1997k), os dois grupos de fenômenos são análogos, mas com valências distintas. Enquanto na vivência da Acrópole prevalece o não reconhecimento de um dado da realidade imediata - o sentimento de "non arrivé" (Freud, 1936/1997k, p. 291) -, nas paramnésias do texto de 1914 prepondera a convicção na factualidade de uma tendência psíquica. Em ambas, constata-se um abalo momentâneo da prova de realidade e um descompasso entre uma tendência psíquica que busca expressão e uma percepção exterior que aguarda reconhecimento.

Defende-se que o primeiro caso se aproxima mais de uma alucinação negativa (Dalgalarrondo, 2000), enquanto o segundo, de uma construção delirante (Freud, 
1911/1997c). Pode-se afirmar que, no episódio da Acrópole, a conexão entre a informação vinculada pela percepção e os conteúdos psíquicos mobilizados por ela só ocorre sob a condição de esvanecimento do Eu. No caso das paramnésias do texto de 1914, uma ideia autorreferente se impõe, condicionando a percepção. Logo, constata-se a insistência preponderante de uma tendência narcísica na apreensão da realidade. Resgatando-se o comentário de Freud (1911/1997c) acerca dos delírios de Schreber, quando afirma que o paranoico ama seu delírio como a si mesmo, é possível descrever a dinâmica psíquica da convicção neurótica na factualidade de suas paramnésias como uma atitude análoga à certeza delirante do psicótico.

De qualquer forma, tanto em um caso como no outro, a fantasia está concernida no seio das paramnésias. De acordo com Freud (1911/1997b), a fantasia é uma zona crepuscular que abriga simultaneamente o funcionamento dos princípios do prazer e da realidade. Freud (1923/1997i) também afirma que ela é uma estrutura que parasita o Eu e que constitui a matriz das formações do inconsciente. Trata-se do solo de onde brotam os sintomas, os sonhos e os atos falhos.

Vale destacar que Freud (1936/1997k) trata o episódio da Acrópole como uma experiência de estranhamento, "Entfremdung” (p. 290). É curioso constatar que ele não faz menção nesse momento ao Unheimliche. Cabe questionar então a relação entre os dois termos. Ainda que no contexto do texto, Unheimliche e Entfremdung possam ser tomados por equivalentes, defende-se que ambos os termos designam fatos correlatos, mas que possuem tonalidades diferentes.

Propõe-se que o Unheimliche poderia ser qualificado como um caso especial do Entfremdung. No primeiro, os sentimentos de desrealização e dessubjetivação estão necessariamente presentes, sendo acompanhados por um esforço de restituição, que tenta soerguer as fronteiras narcísicas e o sentimento de realidade. No caso do estranhamento, a desrealização, a dessubjetivação e a restituição narcísica são elementos contingentes. Para a sua caracterização, basta um descompasso entre uma tendência psíquica interna que busca expressão e um dado da percepção que aguarda a chancela de realidade. Logo, o estranhamento (Entfremdung) pode assumir uma vasta gradação, alcançando o seu paroxismo, no caso das neuroses, no Infamiliar (Unheimliche).

Os atos falhos, por sua vez, constituem um território mais amplo, onde os sentimentos de estranhamento e Infamiliar estão inseridos. Vale lembrar que os atos falhos (Fehlleistungen) (Freud, 1901/1999) podem passar despercebidos. Isto é, eles são capazes de ganhar expressão sem que ocorra a mobilização da censura do Eu. Há ainda a possibilidade 
dos atos falhos, no caso do insucesso de seus disfarces, desencadearem inibição e vergonha, ou mesmo serem suprimidos antes de sua conclusão. Eles podem inclusive desencadear surpresa ou mesmo riso. Tais reações constituem um sinal do reconhecimento da origem intrapsíquica dos conteúdos manifestos e da sua implicação na relação com uma alteridade. De qualquer forma, é possível afirmar que não há obrigatoriamente a irrupção do sentimento do Infamiliar ou de estranhamento em consequência da produção de um ato falho. Essa questão é retomada no próximo tópico a partir do comentário de um texto de Tausk.

\section{Infamiliar, Estranho e Fenômeno Transicional}

Para avançar na apreciação da dinâmica psíquica que leva a irrupção do sentimento de estranhamento, comenta-se um curto texto de Tausk (1919/1983) em que o autor aborda um episódio semelhante ao vivido por Freud e Borges, mas com uma diferença marcante: o sentimento do Estranho (Fremd) provocado por uma paramnésia não evolui para o Infamiliar (Unheimliche). É importante destacar ainda dois elementos importantes nesse curto texto de Tausk: a sua publicação no mesmo ano do ensaio freudiano sobre o Unheimliche, 1919, e o destaque dado ao adjetivo/substantivo Fremd, que comparece como raiz do termo Entfremdung do artigo de Freud de 1936. Em português: estranhamento.

Tausk (1919/1983) descreve o sentimento de perplexidade de um colega, o senhor B., ao se confrontar com o busto do escritor e dramaturgo norueguês H. J. Ibsen (1828-1906). O senhor B., embora bastante familiarizado com a obra e a biografia de Ibsen, fica paralisado e confuso diante da estátua com as feições do escritor. Ele indaga então acerca da identidade da pessoa retratada. Tausk (1919/1983) responde, de forma um tanto irônica, que se trata do farmacêutico, “Apoteker" (p. 289), profissão que Ibsen desempenhou simultaneamente à atividade de escritor. Ele descreve então uma série de pensamentos que afloraram na mente do seu interlocutor a partir da palavra farmacêutico. Tais pensamentos, comenta Tausk, estavam vinculados à memória de uma situação conflituosa de cunho sexual, que, em função da associação com o ofício paralelo de Ibsen, tornaram-se obstáculo ao reconhecimento das feições do escritor. Nesse instante, o referido busto, que até então havia passado despercebido, torna-se Estranho, "Fremd" (Tausk, 1919/1983, p. 290).

Diferentemente do episódio da Acrópole, o senhor B. reconhece a realidade do que lhe chega pela percepção. Nesse caso, ocorre uma espécie de inibição ou desconexão temporária entre o que ele esperava encontrar e o que ele de fato vê. Constata-se nesse episódio a influência de um complexo associativo que se encontrava em estado latente e que se torna 
ativo a partir de um estímulo desencadeador. A informação perceptual é aferida, mas seus nexos com os traços de memória que correspondiam aos detalhes do escritor norueguês são suspensos.

A estranheza que essa experiência produz se refere à desvinculação temporária de elementos já conhecidos, que se tornaram inacessíveis à rememoração voluntária. Trata-se de uma dinâmica similar ao esquecimento de uma palavra que está na iminência de ser rememorada, mas que não vem à luz (Freud, 1901/1999). Não há, portanto, nesse episódio, uma elisão das fronteiras do $\mathrm{Eu}$ ou um abalo do sentimento de consistência da realidade. A diferença dessa experiência com a narrada por Freud no episódio da Acrópole está na gradação do nível de estranhamento, que, no último caso, evolui para o sentimento do Infamiliar (Unheimliche).

Do exposto, considera-se lícito estabelecer uma aproximação das descrições do Unheimliche e do Entfremdung freudianos com os fenômenos que Winnicott (1953/1975) denomina transicionais. Tais fenômenos, segundo o autor, são experiências estruturantes que se formam a partir da relação entre a mãe e o bebê, que produzem um espaço de ilusão por meio do qual a criança conquista gradualmente o acesso à realidade. Nas palavras do autor, os fenômenos transicionais constituem uma zona intermediária entre os processos subjetivos vivenciados como internos e os fenômenos objetivamente percebidos. Os objetos transicionais, por sua vez, são aqueles que ainda "não fazem parte do corpo do bebê", mas que também "não são plenamente reconhecidos como pertencentes à realidade externa" (p. 14).

Nesse espaço intermediário entre os processos internos e a realidade, localiza-se o fantasiar, que, segundo Winnicott (1953/1975) constitui uma zona informe, em certa medida independente da exigência da prova de realidade, que assume a função de depositário virtual das vivências subjetivas. Para o autor, os conteúdos da fantasia adquirem expressão concreta no brincar, no exercício da criatividade e nos vínculos transferenciais.

Winnicott (1953/1975) relaciona ainda os fenômenos transicionais à atividade simbólica. Para ele, o símbolo só se constitui a partir do reconhecimento de uma perda, que são significadas em função das ausências da mãe, pressupondo-se que a pessoa que exerce essa função desempenhou de forma suficientemente boa uma relação de cuidado. Isto é, que foram garantidas para a criança as condições para que ela se relacionasse ilusoriamente com o seio, ou um equivalente dele, tomando-o inicialmente como uma parte do próprio corpo que vai gradualmente se destacando e se autonomizando. Depreende-se daí um trabalho de desilusão, por meio do qual esse objeto transicional - o seio - é desinvestido e internalizado. 
Em termos metapsicológicos, pode-se afirmar: ele é elevado à condição de objeto perdido e passa a compor o núcleo da fantasia. A partir daí, estabelece-se um espaço relacional de investimento que outros objetos do mundo externo poderão ocupar. Tal espaço constitui uma mediação entre as experiências socialmente compartilhadas e as vivências subjetivas mais íntimas. Vale frisar que tais fenômenos transicionais, acompanhados ou não de vivências de desrealização e de dessubjetivação, estão em ação durante todo o curso da vida e não apenas na primeira infância. No entanto, se os sentimentos do Infamiliar e de estranhamento podem ser considerados modalidades do fenômeno transicional, o inverso não é verdadeiro: nem todos os fenômenos transicionais correspondem às vivências do Unheimliche e do Entfremdung. Um argumento importante para essa distinção está no fato de que as experiências de prazer são determinantes para a constituição dos fenômenos transicionais; enquanto no Infamiliar se encontra mobilizada uma dimensão pulsional para além do princípio do prazer que concerne diretamente às repetições.

\section{Considerações Finais}

A título de uma síntese provisória, propõe-se a seguinte relação entre o ato falho (Fehlleistung), o Estranho ou estranhamento (Fremd/Entfremdung) e o Infamiliar (Unheimliche): entende-se que eles constituem categorias correlacionadas, mas que não podem ser tomadas por sinônimos. A sequência acima delineada transmite a ideia de uma gradação que vai do mais genérico ao mais específico. Tal série está organizada em função da qualidade do material recalcado que retorna e da mobilização ou não dos sentimentos de desrealização e dessubjetivação.

Entende-se que ato falho é a expressão com sentido mais abrangente. Ele inclui os dois outros termos da série. O sentimento de Estranho ou estranhamento, por sua vez, pode prescindir da desrealização e da dessubjetivação. Sua especificidade está no desencadeamento de uma vivência de desprazer por meio da mobilização do afeto de angústia, de uma formação reativa ou uma inibição. $\mathrm{O}$ efeito do estranhamento reside na convicção da presença de uma dissonância, de algo inacessível que escapa, mas que é, ainda que parcialmente, reconhecido e simbolizado, desencadeando uma retração do investimento narcísico.

Já o Infamiliar pressupõe uma vivência de esvanecimento subjetivo mais radical, que resulta da mobilização de conteúdos psíquicos mais arcaicos até então em latência. Tais conteúdos estão relacionados aos restos do recalque primário, que permaneceram apartados do processo de desenvolvimento psíquico, sem se beneficiar da evolução dos mecanismos de 
elaboração simbólica. Eles compõem uma parcela mais opaca da fantasia, que se encontra mais próxima do Isso $(E s)$ e mais refratária a influência do Eu (Ich). Pode-se dizer que tais conteúdos reverberam a cicatriz do núcleo da cisão (Spaltung) do Eu. Decorre daí que a sua irrupção produz um efeito de dessubjetivação e desrealização.

Uma aproximação entre os três elementos da sequência e o conceito winnicottiano de fenômeno transicional foi sugerida em razão da mobilização da estrutura da fantasia e do endereçamento a uma alteridade que eles pressupõem. No entanto, foram feitas algumas reservas em relação à inclusão dos fenômenos transicionais na categoria do Infamiliar.

Tomou-se o conto de Borges e o relato da vivência de Freud na Acrópole como exemplos de manifestações do Unheimliche, a partir dos quais se buscou vislumbrar os contornos da arquitetura desse sentimento. Defende-se que na clínica psicanalítica, assim como na literatura, a vivência do Infamiliar não deve ser avaliada exclusivamente em função de seus aspectos desagregadores, produtores de adoecimento ou sofrimento. O Unheimliche pode ser caracterizado como uma experiência de indeterminação simbólica (Dunker, 2011) que pode ter um desfecho produtivo, na medida em que franqueia um movimento de abertura à alteridade, promovendo uma mudança de posição subjetiva e, eventualmente, a elaboração de conteúdos psíquicos que normalmente são mais refratários à influência do processo secundário. Salienta-se que os efeitos de desorientação e vertigem atrelados a ele, quando acompanhados de uma ancoragem simbólica, de um tempo de elaboração e da possibilidade de um endereçamento, podem se transmutar em uma experiência promotora de saúde e de um viver criativo.

\section{Referências}

Borges, J. L. (2009). O Livro de Areia. São Paulo: Companhia das Letras. (Obra original publicada em 1975)

Cesarotto, O. (1996). No Olho do Outro: "O homem de areia" segundo Hoffman, Freud e Gaiman. São Paulo: Iluminuras.

D’Agord, M. R. L., Triska, V. H. C., Sudbrack, R. P., \& Sippert, C. A. (2012). Da Inquietante Estranheza ao Estranhamento enquanto Método. Revista Mal-estar e Subjetividade, 12(1-2), 243-264. Recuperado de http://pepsic.bvsalud.org/pdf/malestar/v12n12/09.pdf

Dalgalarrondo, P. (2000). Psicopatologia e semiologia dos transtornos mentais. Porto Alegre: Artmed. 
Dunker, C. I. L. (2011). Estrutura e constituição da clínica psicanalítica: Uma arqueologia das práticas de cura, psicoterapia e tratamento. São Paulo: Annablume.

Freud, S. (1997a). Drei Abhandlung zur Sexualität. In S. Freud, Studienausgabe (Vol. 5, pp. 37-146). Frankfurt a. M.: S. Fischer, 1997. (Obra original publicada em 1905)

Freud, S. (1997b). Formulierung über die zwei Prinzipien des psychischen Geschehens. In S. Freud, Studienausgabe, (Vol. 3, pp. 13-24). Frankfurt a. M.: S. Fischer. (Obra original publicada em 1911)

Freud, S. (1997c). Psychonalytische Bemerkungen über einen Autobiographisch Beschriebenen Fall von Paranoia. In S. Freud, Studienausgabe (Vol. 7, pp. 133-203). Frankfurt a. M.: S. Fischer. (Obra original publicada em 1911)

Freud, S. (1997d). Über fausse recoinnassance (dejà raconté) während der psychoanalitische Arbeit. In S. Freud, Studienausgabe, v. Ergänzungsband (pp. 231-238). Frankfurt a. M.: S. Fischer. (Obra original publicada em 1914)

Freud, S. (1997e). Zur Einführung des Narzissmus. In S. Freud, Studienausgabe (Vol. 3, pp. 37-68). Frankfurt a. M.: S. Fischer. (Obra original publicada em 1914)

Freud, S. (1997f). Vergänglichkeit. In S. Freud, Studienausgabe (Vol. 10, pp. 223-228). Frankfurt a. M.: Fischer Verlag. (Obra original publicada em 1916)

Freud, S. (1997g). Das Unheimliche. In S. Freud, Studienausgabe (Vol. 4, pp. 241-274). Frankfurt a. M.: Fischer Verlag. (Obra original publicada em 1919)

Freud, S. (1997h). Jenseits des Lustsprinzips. In S. Freud, Studienausgabe (Vol. 3, pp. 241274). Frankfurt a. M.: Fischer Verlag. (Obra original publicada em 1920)

Freud, S. (1997i). Das Ich und das Es. In S. Freud, Studienausgabe (Vol. 3, pp. 241-274). Frankfurt a. M.: Fischer Verlag. (Obra original publicada em 1923)

Freud, S. (1997j). Neue Folge der Vorlesungen zur Einführung in die Psychoanalyse - 31. Vorlesung: Die Zerlegung der psycheschen Persönlichkeit. In S. Freud, Studienausgabe (Vol. 2, pp. 496-516). Frankfurt a. M.: S. Fischer. (Obra original publicada em 1933)

Freud, S. (1997k). Eine Erinnerungsstörung auf der Akropolis (Brief an R. Rolland). In S. Freud, Studienausgabe (Vol. 4, pp. 241-274). Frankfurt a. M.: Fischer Verlag. (Obra original publicada em 1936)

Freud, S. (19971). Die Ichspaltung im Abwehrvorgang. In S. Freud, Studienausgabe (Vol. 3, pp. 389-396). Frankfurt a. M.: Fischer Verlag. (Obra original publicada em 1940)

Freud, S. (1999). Psychopatologie des Alltagslebens. In S. Freud, Gesammelte Werke (Vol. 4, pp. 1-310). Frankfurt a. M.: Fischer Verlag. (Obra original publicada em 1901) 
Freud, S. (2001). Eine Schwierigkeit der Psychoanalyse. In S. Freud, Abriss der Psychoanalyse: Einführende Darstellungen (pp. 185-194). Frankfurt a. M.: Fischer Taschenbuch Verlag. (Obra original publicada em 1917)

Gay, P. (1989). Freud: Uma vida para nosso tempo. São Paulo: Companhia das Letras.

Hans, L. A. (1996). Estranho, sinistro, inquietante, macabro: das Unheimliche. In L. A. Hans, Dicionário comentado do alemão de Freud (pp. 231-239). Rio de Janeiro: Imago.

Iannini, G., \& Tavares, P. H. (2019). Freud e o Infamiliar. In Freud, S. (2019). O Infamiliar (pp. 5-22). Belo Horizonte: Autêntica.

Lacan, J. (1995). O seminário - livro 4: A relação de objeto. Rio de Janeiro: Jorge Zahar. (Obra original publicada em 1956-1957)

Lacan, J. (1997). O seminário - livro 7: A ética da psicanálise. Rio de Janeiro: Jorge Zahar. (Obra original publicada em 1959-1960)

Lacan, J. (1998). O seminário - livro 11: Os Quatro Conceitos Fundamentais da Psicanálise. Rio de Janeiro: Jorge Zahar. (Obra original publicada em 1964)

Martins, K. P. H. (2014). Sertão e melancolia: Espaços e fronteiras. Curitiba: Ed. Appris.

Massechelein, A. (2011). The unconcept: The freudian uncanny in late-twentieth-century teory. Albany (NY): State of University of New York Press.

Mezan, R. (2013). Freud: A trama dos conceitos. São Paulo: Perspectiva.

Numberg, H., \& Federn, E. (2015). Os primeiros psicanalistas: Atas da Sociedade Psicanalítica de Viena 1096-1908. São Paulo: Scriptorium.

Portugal, A. M. (2006). O vidro da palavra: O estranho, literatura e psicanálise. Belo Horizonte: Autêntica.

Rabêlo, F. C., Pereira, G. F., \& Furtado, L. A. R. (2011). Algumas considerações sobre o sujeito e o tempo a partir do conto O Outro de Borges. Revista Mal-estar e Subjetividade, 11(3), 1055-1082. Recuperado de http://pepsic.bvsalud.org/pdf/malestar/v11n3/07.pdf

Rank, O. (1914). Der Doppelgänger. Imago: Zeitschrift für Anwendung der Psychoanalyse auf die Geisteswissenschaften, 3(2), 97-164. Recuperado de https://digi.ub.uniheidelberg.de/diglit/imago1914/0112

Severino, A. J. (3013). Metodologia do trabalho científico. São Paulo: Cortez.

Tausk, V. (1983). Ibsen, der Apoteker. In V. Tausk, Gesammelte psychoanlitische und literarische Schriften (pp. 245-287). Viena, Berlim: Medusa. (Obra original publicada em 1919) 
Winnicott, D. (2000). O desenvolvimento emocional primitivo. In D. Winnicott, Da pediatria à Psicanálise (pp. 218-232). Rio de Janeiro: Imago. (Obra original publicada em 1945)

Winnicott, D. (1975). Objetos Transicionais e fenômenos transicionais. In D. Winnicott, $O$ brincar e a realidade (pp. 389-408). Rio de Janeiro: Imago. (Obra original publicada em 1953)

\section{Endereço para correspondência}

\section{Fabiano Chagas Rabêlo}

Rua Alfeu Aboim, 535 apto 801, Fortaleza - CE, Brasil. CEP 60175-375

Endereço eletrônico: fabrabelo@gmail.com

\section{Karla Patrícia Holanda Martins}

Rua República do Líbano, 961 apto 901, Fortaleza - CE, Brasil. CEP 60160-140

Endereço eletrônico: kphm@uol.com.br

Recebido em: 23/09/2019

Reformulado em: 05/10/2020

Aceito em: 01/12/2020

\section{Notas}

* Professor da UFDPar - Universidade Federal do Delta do Parnaíba. Doutorando em Psicologia pela UFC Universidade Federal do Ceará. Participante da Escola Letra Freudiana.

** Psicanalista, professora nos cursos de graduação e pós-graduação em psicologia da UFC - Universidade Federal do Ceará - Doutora em teoria Psicanalítica pela UFRJ - Bolsista PQ do CNPQ.

Este artigo de revista Estudos e Pesquisas em Psicologia é licenciado sob uma Licença Creative Commons Atribuição-Não Comercial 3.0 Não Adaptada. 